\title{
ESTUDO DE CASO: APLICAÇÃO DA METODOLOGIA SENAI DE EDUCAÇÃO PROFISSIONAL NO CURSO TÉCNICO EM AUTOMAÇÃO INDUSTRIAL A DISTÂNCIA.
}

GOIÂNIA/GO JULHO/2018

\author{
Caio Dias Cordeiro Inocencio－FIEG - caiodias.senai@sistemafieg.org.br \\ Larissa Rodrigues Custodio - FIEG - larissacustodio@sistemafieg.org.br \\ Leovir Cardoso Aleluia Junior - SENAI - leovir.engmecatronica@gmail.com
}

Tipo: Relato de Experiência Inovadora (EI)

Categoria: Métodos e Tecnologias

Setor Educacional: EDUCAÇÃO MÉDIA E TECNOLÓGICA

\begin{abstract}
RESUMO
O presente artigo trata de um caso prático de aprendizagem significativa implementado em uma turma do Curso Técnico em Automação Industrial a distância no Serviço Nacional de Aprendizagem Industrial de Goiás, cujo objetivo é abordar a metodologia de ensino utilizada para incentivar o aluno a aprender, e, sobretudo conhecer a importância da interdisciplinaridade dos conhecimentos adquiridos ao longo do curso no mercado de trabalho.

Os projetos implementados pelos alunos foram pensados e desenvolvidos a distância $e$ presencialmente, assistidos articuladamente pelo tutor online, professor presencial e coordenadores técnicos de curso. Os alunos utilizaram, como interação, o ambiente virtual de aprendizagem para definição dos projetos, assim como elaboração de cronogramas de atividades, manuais, diagramas e apresentações. A escola foi utilizada, com o apoio do professor presencial, como espaço de encontro físico para implementação das ideias discutidas no ambiente virtual, com a condução do tutor online. Desta forma, percebe-se a integração entre o espaço virtual e a escola para elaboração e execução das tarefas pelos alunos.

A metodologia aplicada para aprendizagem possibilitou ao aluno compreender os conhecimentos adquiridos ao longo do curso como um todo para sua formação profissional e compreender a aplicabilidade desses conhecimentos no mercado de trabalho.
\end{abstract}

Palavras-chave: Metodologia Senai de Educação Profissional. Situação de Aprendizagem. Autonomia. Conhecimento. Automação Industrial. Projeto. Aprendizagem Significativa. 


\section{Introdução}

O avanço tecnológico e científico tem proporcionado aos alunos extensa facilidade de acesso a informação ocasionando uma revolução na educação. Ensinos atados e ordenados em técnicas de memorização são hábitos desatualizados que ainda são utilizados por alguns docentes e não fazem parte do cotidiano dos estudantes modernos. Desta forma, estas práticas obsoletas não promovem uma formação integral contextualizada impedindo o aluno a assimilar a aprendizagem com a realidade profissional vivida no mercado de trabalho. Percebe-se a necessidade de reformulação de algumas estratégias e procedimentos pedagógicos para a prática docente (PEIXOTO, 2016; OLIVEIRA, 2017), especialmente com o uso de tecnologias educacionais de informação e comunicação.

De acordo com as Normativas Educacionais Brasileiras (LDB 9394/96, PCNEM 1998, 2000), o ensino deve oportunizar aos jovens uma formação capaz de prepará-los para a vida. O que significa, entre outras atribuições, que além de interpretar ou reproduzir dados, os alunos deverão ser capazes de refletir e posicionar-se criticamente diante de fatos da realidade participando socialmente das decisões.

Depreende-se a necessidade de implementação de uma metodologia de ensino que permita acompanhar o desenvolvimento das competências dos estudantes para garantir a continuidade e contextualização da aprendizagem de forma autônoma e crítica.

\section{Objetivos}

O objetivo deste trabalho é abordar a Metodologia Senai de Educação Profissional utilizada para influenciar o aluno a aprender e sobretudo assimilar a importância da interdisciplinaridade dos conhecimentos adquiridos ao longo do curso preparando para o mercado de trabalho. É abordado um estudo de caso prático onde os princípios norteadores da prática docente do SENAI são implementados em uma turma do curso de habilitação técnica em automação industrial a distância.

\section{Referencial teórico}

A Metodologia SENAI de Educação Profissional permite ao aluno reconhecer o real significado daquilo que está sendo aprendido através de um conjunto de ações que norteiam a prática docente capazes de mobilizar conhecimentos, habilidades e atitudes através de contextos reais e profissionais. 
Os princípios norteadores da prática docente do SENAI são: i) integração entre teoria e prática; ii) interdisciplinaridade; iii) aprendizagem significativa; iv) incentivo ao pensamento criativo e a inovação; v) ênfase no aprender a aprender; vi) desenvolvimento das capacidades; vii) aproximação ao mundo de trabalho; viii) mediação da aprendizagem; ix) avaliação diagnóstica, formativa e somativa; e x) contextualização (Metodologia SENAI de Educação Profissional, 2013).

Os dez princípios mencionados favorecem a organização dos processos de ensino e aprendizagem possibilitando a construção de novos conhecimentos e o desenvolvimento de capacidades. Estes princípios surgiram de contribuições dos autores Vygotsky (2007, 2010), Piaget (1998, 2011), Ausubel (1980) e Perrenoud (1999, 2000).

A mediação pedagógica entre o ensino docente e aprendizagem aluno ocorre em meio de situações de aprendizagens planejadas de forma que contemplem uma estratégia de aprendizagem desafiadora, abordando uma contextualização da atividade e informando os fundamentos técnicos, científicos e também as capacidades sociais, organizativas e metodológicas. Essas informações estão reunidas em um só formulário chamado de: plano da situação de aprendizagem.

O aperfeiçoamento e a execução das capacidades que oportunizam ao aluno deslindar situações mais difíceis no cotidiano ocorrem em virtudes de intervenções mediadoras que sustentam de forma consciente a construção da aprendizagem significativa.

O grande desafio que envolve a metodologia é preparar todos os profissionais envolvidos, pois depende de uma supervisão cautelosa e avaliação sistemática de realização, de modo que se possa contrastar os impactos na evolução das capacidades dos alunos e, em decorrência, no perfil dos concluintes.

É primordial que o docente utilize dos diversos tipos de recursos didáticos no decorrer de uma situação de aprendizagem. Os mais eficazes são: recursos multimídias (TV, projetor, computador, aparelho de som) livros virtuais, slides, kits didáticos, aplicativos em dispositivos móveis e no caso do curso Técnico em Automação Industrial EaD o uso de simuladores virtuais que englobam as novas gerações e os conceitos de indústria 4.0.

\section{Procedimentos metodológicos}

O trabalho apresenta um estudo de caso implementado em uma turma do curso técnico em automação industrial a distância do SENAI. O curso é composto por doze unidades 
curriculares. A décima unidade curricular, nomeada por Desenvolvimento de Sistemas de Controle, foi utilizada como objeto de estudo. Esta unidade curricular tem carga horário total de cem horas, sendo oitenta a distância e vinte presenciais. O objetivo geral é propiciar o desenvolvimento das capacidades técnicas, sociais, organizativas e metodológicas requeridas para a implementação de equipamentos e dispositivos de controle e automação.

A situação de aprendizagem utilizada na unidade curricular para que o aluno alcance as competências necessárias é dividida em 3 etapas, sendo estas: i) desenvolvimento do planejamento e análise de viabilidade do projeto selecionado pelos alunos; ii) desenvolvimento do relatório final e apresentação do projeto e iii) desenvolvimento do manual de instalação, operação e manutenção do projeto.

As atividades foram desenvolvidas de forma que ao final da unidade curricular os alunos trabalhassem com determinadas competências, que são a mobilização das habilidades de conhecimentos para resolver um determinado problema, requeridas ao técnico em automação industrial. Todas estas são descritas no plano de curso. As competências são determinadas a partir de um perfil profissional que é traçado por um comitê técnico setorial formado por docentes da área, coordenadores técnicos e pedagógicos, representantes de sindicatos, de grandes empresas do mercado e do poder público para garantir a formação profissional e a aplicabilidade desses conhecimentos no trabalho.

A seleção dos integrantes e dos temas dos projetos dos grupos foi realizada pelos próprios alunos com a utilização de fóruns de comunicação postados no AVA (Ambiente Virtual de Aprendizagem) e também com auxílio da plataforma de mensagens instantâneas Whatsapp com o acompanhamento do tutor.

O tutor, que de acordo com a Portaria MEC n․ 4.059 (2004), é o "docente qualificado em nível compatível ao previsto no projeto pedagógico do curso, com carga horária específica para os momentos presenciais e os momentos a distância". No SENAI GO ele fica responsável por elaborar, postar, corrigir e dar feedback sobre a correção de todas as atividades envolvidas dentro da situação de aprendizagem. Já o professor presencial fica com a responsabilidade de aplicar aos alunos, a teoria estudada, em forma de aulas práticas em laboratórios utilizando plantas industriais, instrumentos, medidores, controladores e microcontroladores. O alinhamento prévio da aula é feito por meio de web conferências e na ocasião o Tutor, além de detalhar como deverá ocorrer a aula para o Professor Presencial, com auxílio de um plano, também informará como está o andamento da turma e a teoria já estudada. Para auxiliar todos esses processos existe a presença de um Coordenador Técnico que dá suporte para o bom andamento entre o 
que há em conteúdo a distância e presencial.

Para seleção e definição dos temas a serem trabalhados foi realizado um alinhamento prévio entre tutor e professor presencial visto a necessidade de saber os equipamentos e componentes disponíveis na unidade presencial.Os alunos foram informados sobre possíveis temas, mas tiveram a autonomia para realizarem alterações nos temas sugeridos ou sugerirem novos temas. Os recursos didáticos que foram disponibilizados aos alunos para elaboração dos projetos foram: i) livro didático da unidade curricular e conteúdo virtual postado no AVA abordando os conhecimentos da atividade; ii) textos, imagens, vídeos e animações interativas disponibilizadas no AVA; iii) pesquisa na internet dos conhecimentos abordados nesta atividade e iv) comunicação síncrona, ou seja em tempo real e assíncrona, para esclarecimentos de conteúdos com o tutor pelo AVA.

O conteúdo didático disponibilizado no AVA, o livro didático online, o esclarecimento de dúvidas dos conteúdos por meio de e-mail, chat no AVA ou Whatsapp, os fóruns e as aulas presenciais foram as estratégias de ensino e aprendizagem utilizadas para mediação do conhecimento da unidade curricular.

De acordo com as legislações brasileiras de educação (Decreto № 9.057/17, LDB 9.394/96) as ações a serem realizadas, em momentos presenciais da educação profissional técnica de nível médio a distância, serão executadas na sede da instituição de ensino, polos ou ambiente profissional. A unidade curricular é composta por dois momentos presenciais com oito horas de duração cada, que acontecem nas escolas e faculdades da própria entidade. O objetivo do primeiro encontro presencial foi sanar às dúvidas pertinentes a elaboração do planejamento e da viabilidade do projeto e instruir os alunos sobre o desenvolvimento de metodologia científica aplicada a projetos. $O$ objetivo do segundo encontro presencial foi a finalização dos projetos com o auxílio do professor presencial e apresentação dos trabalhos.

\section{Apresentação e discussão dos resultados}

A turma de alunos do curso utilizada como objeto de estudo era integrada por vinte e oito estudantes que foram divididos em cinco grupos compostos por no máximo seis pessoas. Após as discussões entre os alunos envolvidos nos grupos em fóruns de discussão no AVA, os temas escolhidos para elaboração dos projetos foram: i) alinhador automático de caixas; ii) melhorias na estufa de secagem de motores; iii) dosador de suco; iv) controle de temperatura e v) movimentação de peças utilizando bancada três eixos. Os projetos i e iii são ilustrados na figura 1, respectivamente: 


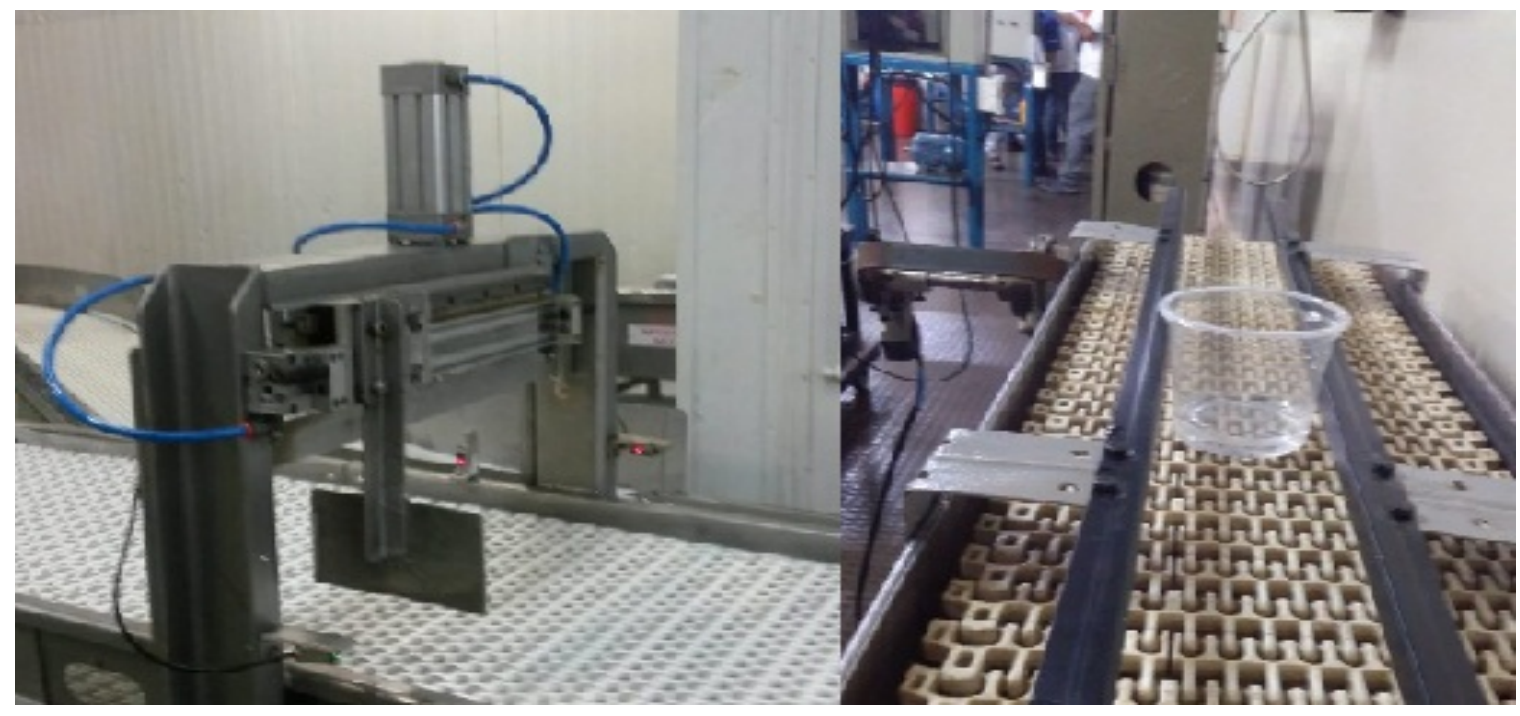

Figura 1 - Projetos desenvolvidos pelos alunos

Entre os projetos elaborados, dois deles foram implementados em indústrias de alimentos da região sudoeste goiana e outros três foram aplicados na própria escola, podendo assim serem usufruidos para estudantes de outras turmas e cursos distintos. Os alunos tiveram autonomia de decisão sobre os locais para execução das atividades, assim como no tema (desde que não fugisse do objetivo do curso) e desenvolvimento, ocasionando o incentivo ao pensamento crítico, a inovação e a aproximação ao mundo de trabalho.

O cronograma com o planejamento das tarefas a serem realizadas, o levantamento de custos de cada etapa, a análise de viabilidade econômica do próprio projeto e a elaboração de diagramas elétricos, mecânicos, pneumáticos e manuais de instalação e manutenção foram ações executadas pelos alunos intermediados pelo tutor através das ferramentas do ambiente virtual de aprendizagem e também do professor presencial na escola, responsáveis pela mediação da aprendizagem.

Para realizar as atividades os alunos tiveram que revisar todo conteúdo dado e buscar os conhecimentos prévios vistos no curso, havendo assim uma interdisciplinaridade dos saberes e também uma aprendizagem significativa. Todos os trabalhos foram apresentados a banca em seminários que ocorreram no segundo encontro presencial. Após a realização das apresentações houve um alinhamento de informações entre o tutor a distância, o professor presencial, e com os coordenadores técnicos no intuito de mensurar os resultados obtidos com a atividade proposta na unidade curricular.

A situação de aprendizagem teve como indicadores: o nível de desempenho dos alunos, mensurado através de critérios definidos como críticos e desejáveis e pontuados de zero 
a cem pontos divididos entre quarenta e nove no AVA e cinquenta e um nos encontros presenciais. Percebe-se então a aplicação dos princípios da prática docente no SENAI GO como incentivo a aprendizagem ao aluno, a interdisciplinaridade, a contextualização, a mediação da aprendizagem o desenvolvimento das capacidades e a ênfase no aprender a aprender.

\section{Considerações finais}

A metodologia aplicada para aprendizagem possibilitou aos alunos compreender os conhecimentos adquiridos para sua formação profissional e a aplicabilidade em projetos e protótipos úteis na realidade da indústria. Desde o princípio os alunos trabalharam de forma colaborativa utilizando recursos didáticos tecnológicos concentrando-se em um ambiente virtual de aprendizagem. O uso de redes sociais foi bem aceito pois propiciou ainda mais interação entre a turma, os integrantes dos grupos, o tutor e o professor.

É notória a evolução da tecnologia da informação e com o mundo cada vez mais globalizado os alunos conseguiram trabalhar de forma próxima, eficaz e didática visto que obteve-se bons resultados com as atividades propostas em que se deram início de forma virtual, a distância, com apoio do tutor, sendo concluídas e apresentadas ao professor no momento presencial do curso. Foram expostos projetos físicos integrando desde as primeiras unidades curriculares do curso até as últimas estudadas, envolvendo assim teoria e prática.

Os novos métodos de ensino, somado as ferramentas tecnológicas disponíveis e compilados por uma metodologia sólida e estruturada disseminam cada vez mais oportunidade de qualidade de ensino a toda população.

\section{Referências}

AUSUBEL, David. Psicologia educacional. Rio de Janeiro: Interamericana, 1980.

GOMES, Annatália Meneses de Amorim et al. Os saberes e o fazer pedagógico: uma integração entre teoria e prática. Educ. rev., Curitiba, n. 28, p. 231-246, Dec. 2006.

DE OLIVEIRA, Elisandra Brizolla et al. Temas geradores como contribuição metodológica para a prática docente. Kiri-Kerê-Pesquisa em Ensino, n. 2, 2017.

PEIXOTO, Anderson Gomes. O uso de metodologias ativas como ferramenta de potencialização da aprendizagem de diagramas de caso de uso. Periódigo Científico 


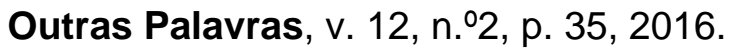

BRASIL. Ministério da Educação e Cultura. LDB - Lei n. 99394/96, de 20 de dezembro de 1996. Estabelece as diretrizes e bases da Educação Nacional. Brasília: MEC, 1996.

BRASIL. Ministério da Educação e Cultura. Portaria n.ำ4059/04, de 13 de dezembro de 2004.

SENAI. Departamento Nacional. Metodologia SENAI de educação profissional. / SENAI. Departamento Nacional. - Brasília: SENAI/DN, 2013. 220 p. : il. ; $21 \mathrm{~cm}$. 